\section{Kidney \\ Blood Pressure \\ Research}

Review

This is an Open Access article licensed under the terms of the Creative Commons Attribution-

\title{
Chronic Kidney Disease (CKD) as a Systemic Disease: Whole Body Autoregulation and Inter-Organ Cross-Talk
}

\author{
Carmine Zoccalia Giovanni Tripepi ${ }^{a}$ Evangelia Dounousi ${ }^{b}$ Francesca Mallamacia, \\ ${ }^{a}$ CNR National Research Council (Italy) Clinical Epidemiology and Physiopathology of Renal Disease \\ and Hypertension Unit, Ospedali Riuniti Reggio Calabria, Italy; ${ }^{b}$ Department of Nephrology Medical \\ School, University of Ioannina Ioannina, Greece; 'Nephrology, Hypertension and Renal Transplantation \\ Unit, Ospedali Riuniti Reggio Calabria, Italy
}

\section{Key Words}

CKD • Risk • Cardiovascular • Progression • ESRD • Phenotype • FGF23 • ADMA • Sympathetic - NPY

\begin{abstract}
The inter-organ cross-talk and the functional integration of organ systems is an exceedingly complex process which until now has been investigated with a reductionist approach. CKD perturbs the inter-organ cross-talk and demands central resetting of autonomic (nervous) control of organ systems. Due to limitations inherent to the reductionist approach, we currently identify CKD-related pseudo-syndromes and largely fail at describing the complex systemic inter-relationships set into motion by renal damage and renal dysfunction. A mature technology for a system-analysis approach to physiology and pathophysiology of CKD now exists. System biology will allow in depth understanding of complex diseases like CKD and will set the stage for predictive, preventive and personalized medicine, a long-standing dream of doctors and patients alike.
\end{abstract}

Copyright (C) 2014 S. Karger AG, Basel

\section{Introduction}

Over the last two decades, clinical nephrologists have been increasingly attracted by biomarkers research as an unique opportunity to make prognostic estimates and to inform clinical decisions about therapy. Biomarkers provide essential information to define clinical phenotypes and as such are central to prognostic and therapeutic research. Creatinine, albumin and other biomarkers including cardiac biomarkers like BNP and pro BNP are precious for the definition of chronic kidney disease (CKD) and of the attendant 


\section{Kidney \\ Blood Pressure Research}

cardiovascular risk. Furthermore the several biomarkers of organ dysfunction which have been discovered over the last decades are intensively applied to perform detailed studies of patho-mechanisms underlying CKD in the clinical scenario and formidable new tools [1] will soon allow the study of the same patho-mechanisms in a dynamic manner, an issue we will touch upon in the closing of this non-systematic overview of the problem. The genome remains of course of fundamental importance but herein we will not deal with genes and genetic epidemiology.

\section{Pathophysiological underpinnings of CKD as a systemic disease: framing the problem}

Growth is perhaps the most fascinating and formidable biological phenomenon in complex organisms. In humans body mass at birth is about three kilograms and in adults is 70 -80 kilograms or over, i.e. $\geq 20$ times higher than at birth. The challenge for the human body during growth and adulthood, is to harmonize the growth of all parts that make up the whole fabric and to maintain the functional coordination of all organ systems which is an extremely complex biological undertaking. This demands that the master regulator, the brain, be closely inter-related with the osteo-muscular apparatus, the cardio-pulmonary system, the kidney and all other organ systems. With this background in mind, I will firstly recapitulate some essential features of systems physiology as envisioned by Guyton to then elaborate on the pathophysiological complexity of CKD, a true systemic disease.

\section{Systems Physiology: Basic concepts and inter-organ cross-talk}

Cardiovascular homeostasis and the pressure-natriuresis curve

The basic graph applied by Guyton to interpret the organ systems response to environmental or endogenous perturbations, plots in a time scale the organ systems response defined in terms of "gain" i.e. the degree to which a feedback system can correct any perturbation of the steady state in the same systems [2], that is, the amount of correction of the deviation -an increase or a decrease of the physiological function in question- divided by the residual degree of deviation. When a control system corrects the effect (a deviation) of a given perturbation minimally, its feedback gain is near to 0 . When it corrects the same effect completely, its gain is infinite. A classic example is the cardiovascular response to factors that perturb blood pressure (BP) (e.g. blood volume loss or overload). As shown in Figure 1, the first system that enters into action when BP deviates from the norm is the baroreceptor system. This system remains operative for up to 16 hours and from there on the gain in such a mechanism declines. Chemoreceptors comes into play simultaneously with baroreceptors but have a lower gain than baroreceptors. Subsequently the ischemic response of the central nervous system, a mechanism with a higher gain, is activated. After about three hours, if the perturbation still persists the kidney enters into action. The kidney is fundamental to compensate the original perturbation in the long term.

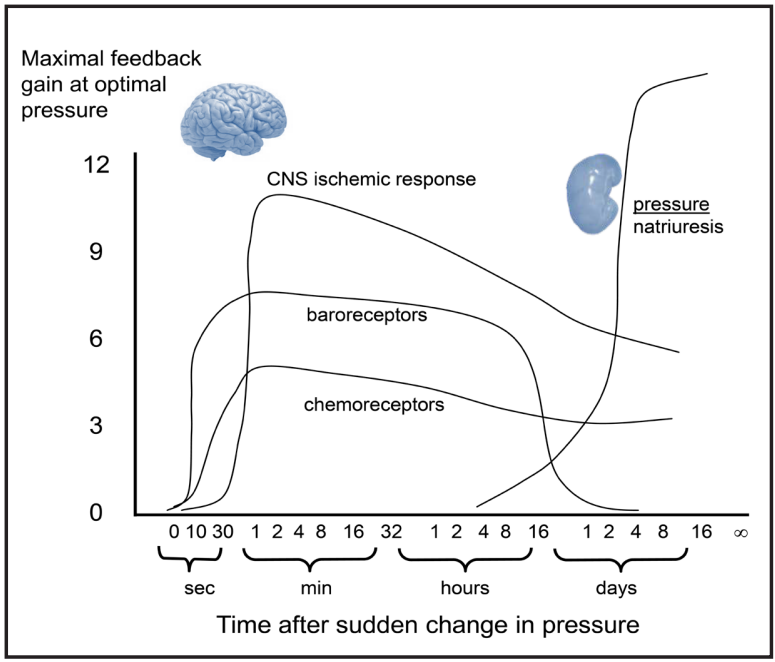

Fig. 1. Response to stimuli the alter BP. The Figure is commented in the main text. 


\section{Kidney Blood Pressure Research}

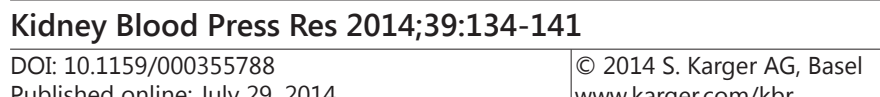

Published onlıne: July 29, 2014

www.karger.com/kbr

Zoccali/Tripepi/Dounousi/Mallamaci: CKD and Inter-Organ Cross-Talk

Indeed the counter-regulatory response of this organ (the pressure-natriuresis curve) has an infinite gain, i.e. the kidney can completely correct the BP deviation. Such a curve shows a characteristic exponential rise followed by an asymptotic phase implying that the kidney opposes the perturbation until the same perturbation remains active. Pressure-natriuresis does not represent a purely renal response. Indeed, the central nervous system exerts a relevant control on the response of the kidney to volume expansion. In volume overloaded rats, the activity of the renal nerves is reduced by 44\%, a response of relevance for the disposal of volume excess by the kidney and for the correction of the BP deviation induced by volume overload [3].

The reach of the central nervous system, the master regulator of organ systems, is of course not limited to the cardiovascular system and extends to all other organ systems including the bone, i.e. an organ which in a not so remote past was considered as a mere mineral storage organ. Indeed, a major neurotransmitter of the sympathetic system, neuropeptide Y (NPY), acts on specific receptors in osteoblasts to restrain osteoblast activity. The relevance of this neural control mechanism in experimental models in vivo is supported by the observation that in the NPY knockout mice trabecular bone volume is almost doubled as compared to wild mice [4].

\section{Inter-organ cross-talk}

Inter-organ cross-talk contributes to global cardiovascular homeostasis. Beyond the nervous system and baroreceptor dependent mechanisms, the heart directly influences the pressure-natriuresis curve by releasing cardiac natriuretic peptides (ANP and BNP). These peptides influence the gain of the BP curve by favoring natriuresis during volume expansion in pathological conditions like heart failure [5]. Likewise, the endothelium exerts a similar renal effect by increasing the synthesis of nitric oxide (NO), a vasodilatory gas endowed with powerful natriuretic properties [6]. NO synthesis is endogenously regulated by asymmetric di-methyl arginine (ADMA), an aminoacid which competes with arginine at the active sites of the enzyme which generates NO (NO synthase) thereby suppressing NO synthesis. ADMA infusion has an antinatriuretic effect in healthy subjects [7] and may participate into the counter-regulatory response to low BP conditions like septic shock (see below). Notably, NO and its main antagonist, ADMA, have opposite effects on the heart. Indeed NO restrains myocardial growth [8] while ADMA, by removing this restraint, promotes left ventricular hypertrophy (LVH) $[9,10]$. Of note ADMA interferes with a fundamental biological function like the regulation of the enzyme telomerase [11], the enzyme that regulates the length of cell telomeres, i.e. the DNA sequence critical for setting cell life span. High ADMA shortens cell telomeres and reduces the life span of endothelial cells.

Over the last few decades numerous studies in experimental models and observational studies in healthy subjects and in patients with heart or kidney diseases, unraveled unsuspected links between mineral metabolism and the cardiovascular system [12]. Mineral metabolism is regulated by three organ systems. The intestine that absorbs environmental calcium and phosphate salts, the kidney that facilitates calcium and phosphate absorption via the synthesis of $1,25(\mathrm{OH})_{2}$ vit $\mathrm{D}_{3}$ that guarantees the excretion of these divalent ions, and the bone that incorporates and stores these ions into a complex (trabecular and cortical) organic-mineral structure. The parathyroid gland is fundamental for the control of circulating calcium and the bone per se has a leading role for the maintenance of phosphate balance via the bone hormone fibroblast growth factor 23 (FGF23), a peptide with powerful phosphaturic and $1,25(\mathrm{OH})_{2}$ vit $\mathrm{D}_{3}$-suppressing effects. To exert its phosphaturic action, FGF23 requires that the tubular FGF receptor is coupled with an obligatory co-receptor, Klotho. Indeed, the Klotho knock-out mouse typically shows hyperphosphatemia and low 1,25 $(\mathrm{OH})_{2}$ vit $\mathrm{D}_{3}$ levels [13]. Due to receptor-resistance, FGF23 levels are substantially raised in this model. FGF23 is also a major myocardial growth factor. Importantly, the FGF receptor in myocardial cells does not require Klotho to respond to circulating FGF23 and therefore the Klotho null mouse develops marked concentric left ventricular hypertrophy (LVH) [14]. Overall, because its myocardial effects, FGF23 triangulates the bone-kidney connection to the heart. 


\section{Kidney Blood Pressure Research}

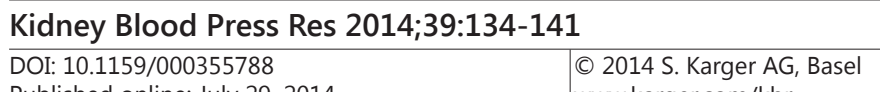

Published onlıne: July 29, 2014

www.karger.com/kbr

Zoccali/Tripepi/Dounousi/Mallamaci: CKD and Inter-Organ Cross-Talk

\section{The pathophysiology underlying CKD as a systemic disease}

The kidney is strictly interconnected with the central nervous system. Afferent renal nerves restrain central sympathetic activity. Experimental models and observations in CKD patients show that reduced renal function associates with parallel increases in efferent sympathetic activity $[15,16]$. Sympathetic activity is almost doubled in dialysis patients and bilateral nephrectomy abrogates such an alteration [17]. Activation of the autonomic system occurs early in CKD and increases progressively as renal function deteriorates [15]. Importantly, the most effective drug class endowed with nephroprotective properties, ACE inhibitors, correct almost completely sympathetic overactivity in CKD patients [18]. A pilot study in patients with stage 3-4 CKD and resistant hypertension suggests a benefit of renal denervation on hypertension control as well as on proteinuria and the GFR [19]. However, this hypothesis-generating study did not contemplate a control procedure (sham renal denervation) and was too small to allow sensible conclusions on the value of renal denervation for hypertension control and attenuation of CKD progression in these patients. Nonetheless, this study is in keeping with data in experimental models in the rat showing that interventions that reduce sympathetic activity mitigate renal damage in the same models [20,21].

We previously alluded to the strong role of the central nervous system, namely of NPY [4], for the maintenance of bone mass in in mice. In this respect, there is circumstantial evidence that this mechanism may be operative in CKD patients. Indeed, plasma NPY is inversely related with bone alkaline phosphatase and with serum PTH in dialysis patients [22], suggesting that, like in experimental models, high levels of this neuropeptide may reduce bone turnover and contribute to the most frequent bone disease in this population, i.e. low-turnover osteodystrophy (Figure 2).

The kidney-heart connection goes far beyond circulating blood volume and extracellular volume homeostasis. Indeed, reduction in renal mass modifies the very expression of a miriad of genes in the heart. Unilateral nephrectomy, acutely halves the GFR. However, due to compensatory renal growth, after just 4 weeks, rats submitted to this intervention reattain a nearly normal GFR and do not develop proteinuria or hypertension while circulating levels of renin and aldosterone as well as body fluids remain within the normal range in this model. Thus unilateral nephrectomy is a model of early, mild CKD. From a biological point of view, it is truly remarkable that even a very modest degree of renal impairment modifies 103 cardiac genes regulating TGF- $\beta$ expression and the apoptosis pathways thereby inducing profound anatomical and functional modifications in the heart. In the intact rat only about the $2.2 \%$ of the heart mass is fibrous, while in the nephrectomized rat the amount of fibrous tissue is doubled, a substantial anatomical change with negative functional (left ventricular end-diastolic dysfunction) implications. Furthermore, cardiac fibrosis and $\mathrm{LV}$ dysfunction gradually progress to more global $\mathrm{LV}$ remodeling (concentric $\mathrm{LVH}$ ) and to systolic dysfunction in this model [23]. The same phenomenon may be operative in CKD. Indeed LV mass increases linearly at progressively lower GFR levels and concentric LVH is the dominant LV geometric pattern in CKD patients [24] while LV fibrosis, as measured by Doppler backscattering [25], goes along with LVH in these patients.

We previously alluded to the fact that the endothelium may influence heart mass and structure. Indeed, NO - a substance mainly synthesized by the endothelium- restrains 


\section{Kidney Blood Pressure Research}

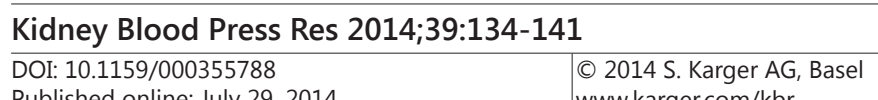

Published onlıne: July 29, 2014

www.karger.com/kbr

Zoccali/Tripepi/Dounousi/Mallamaci: CKD and Inter-Organ Cross-Talk

LV growth while the endogenous NO inhibitor ADMA triggers LVH. The relevance of the endothelium-heart link in CKD is documented by the strong association between concentric LVH and plasma ADMA levels in dialysis patients [10], an association which extends to predialysis CKD patients [26, 27].

Of relevance, beyond the cardiovascular system, high ADMA levels impinge upon kidney function and on the structural integrity of the same organ. In rats with unilateral nephrectomy, i.e. a model of early CKD, continuous ADMA infusion by minipumps induces the local synthesis of TGF- $\beta$ eventuating in marked interstitial renal fibrosis [27]. In keeping with findings in this model, renal fibrosis is a hallmark in the remnant kidney model (5/6 renal ablation). The importance of ADMA in renal fibrosis in the remnant model is demonstrated by experiments showing that transfection of the enzyme that degrades ADMA, dimethylarginine dimethylaminohydrolase (DDAH) reduces the expression of TGF - $\beta$ and prevents fibrosis [28]. ADMA is likely implicated in renal damage also in humans because in 2 cohort studies, respectively in old [29] and middle age CKD [30] patients, high levels of this methylarginine associated with faster CKD progression and proteinuria.

Evidence that high ADMA may have deleterious effects on the heart and the kidney was gathered more than a decade ago. Yet, notwithstanding drugs that may reduce or antagonize ADMA are already available, therapeutic research aimed at countering the adverse effects of this substance lags far behind pathophysiological and clinical knowledge. Sluggish progress in this area is due to the almost uniquely complex inter-relationships of the NO system with cell biology and organ function. Indeed, depending on the clinical context, high ADMA may turn out to be a protective, life-saving, compound. For example, inhibition of DDAH in septic shock, a condition characterized by profound vasodilatation attributable to the massive synthesis of NO by inducible NO synthase, determines a higher survival in rats with experimental septic shock [31].

In complex organisms inter-organ cross-talk is a widespread, fundamental phenomenon for life and goes far beyond the heart and vascular system cross-talk or the cross-talk between the cardiovascular system and the kidney we have just touched upon. This phenomenon extends to the liver, to energy storage and energy processing organs like the adipose tissue and the pancreas and other organs. Of utmost importance, we have now evidence that an apparently secluded, mainly mineral, organ characterized by low turnover like the bone profoundly affects heart anatomy and function and renal function. We have previously alluded to the powerful effect of FGF23 (a bone hormone) on left ventricular mass [14] and to the parallel effect on the same parameter by ADMA [10, 26]. Intriguingly, recent data show that FGF23 interacts in a competitive fashion with ADMA to determine the risk for CKD progression in patients with renal diseases [32]. Both ADMA and FGF23 are inversely related with the GFR and the serum concentration of these substances increases in parallel as renal function deteriorates. More importantly, if we stratify CKD patients on the basis of FGF23 levels, the risk of progression toward kidney failure by a fixed increase in ADMA gradually increases at progressively lower FGF23 levels while there is no risk excess by ADMA in patients with low FGF23 levels. This observation conforms to experimental evidence in genetically engineered animals showing that in the $\mathrm{K}^{+/-}[33,34]$ mice, i.e. a model characterized by high FGF23 levels, exhibits a marked impairment in NO synthase gene expression. Thus observations in CKD patients and in experimental models suggests that these two factors, namely a bone hormone and an endothelial factor, are on the same pathway that leads to CKD progression.

\section{Perspectives}

We made examples of several inter-organ talks an focused on two or at most three interorgan relationships. Admittedly, this is a too simplistic, reductionist approach. The reality is very complex and interactions cannot be properly framed and understood by adopting a reductionist approach to the problem. This is exemplified by conditions characterized by 


\section{Kidney Blood Pressure Research}

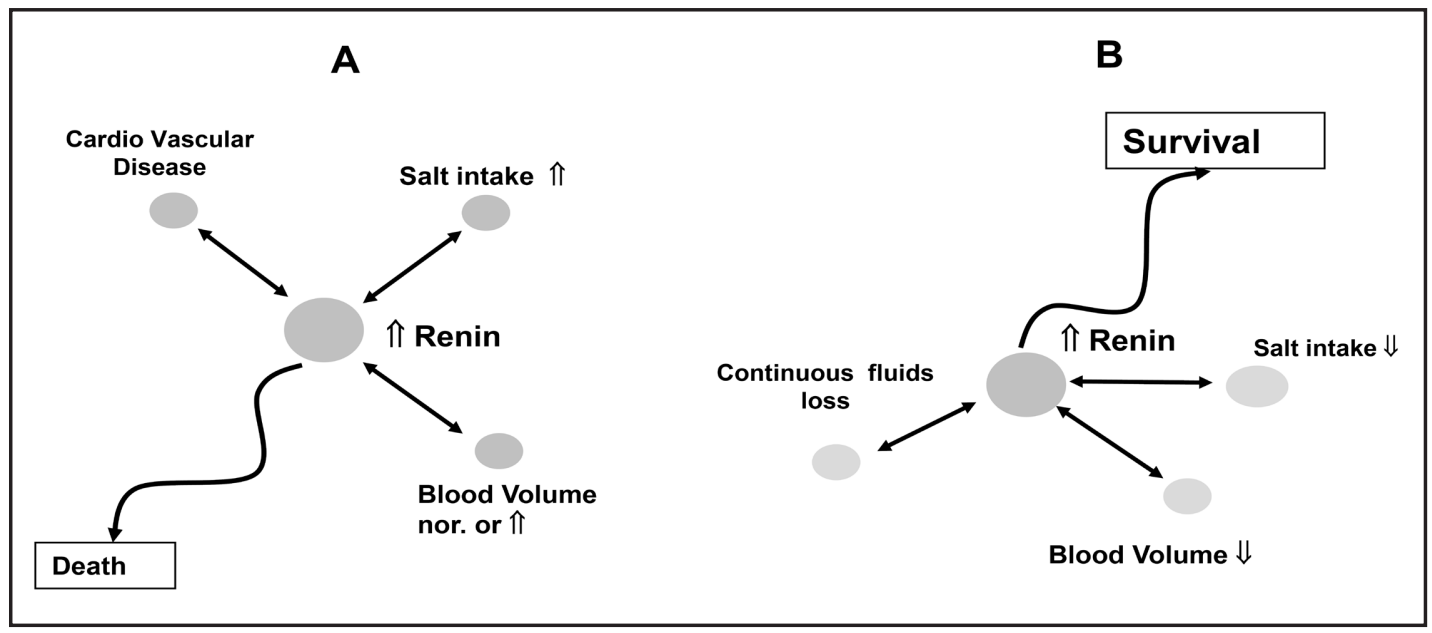

Fig. 3. Context dependent effects of the activation of the Renin-Angiotensin system with survival. The figure is commented in the main text.

high renin. The health effects of high renin are characteristically context-dependent. High renin in the setting of high salt intake, blood volume expansion and cardiovascular disease associates with reduced survival (Figure 3, A). However, when high renin is associated with fluid loss and/or low salt intake, i.e. when this alteration represents a counter-regulatory response to low blood volume, it associates with longer rather than reduced survival (Figure 3 , B). To understand the consequences of the modification of a given biological factor we must look at the several effects that this factor may trigger and to concomitant factors that may modify the effects of the factor in question. The complexity is tantalizing because biological variables connected to the factor in question change over time and therefore to fully understand the chain of events set into motion when we alter the same factor we need to acquire longitudinal information on the whole network of variables connected to the factor of interest. The present reductionist approach to pathophysiology of CKD is like exploring a dark environment by candlelight. In the dark, we see just pieces of an exceedingly complex scenario and identify syndromes that do not exist, like the cardio - renal syndrome, the cardio - renal anemia, the CKD-MBD syndromes and the likes. We have detailed elsewhere the inconsistencies and the weaknesses of the so called "cardio-renal" syndrome [35] and more recently a similar critique has been advanced to the "CKD-MBD" syndrome [36]. Yet we have now new instruments for exploring the complexity of CKD. Metabolomics and metabonomics allow us to identify detailed risk profiles and to measure precisely the components of this profile. We can now investigate the evolution of risk profiles for CKD overtime rather than follow the mere longitudinal changes of a single or just a few factors.

\section{Conclusion}

The inter-organ cross-talk and the functional integration of organ systems is an exceedingly complex process which until now has been investigated with a reductionist approach. CKD perturbs the inter-organ cross-talk and demands central resetting of autonomic (nervous) control of organ systems. Due to limitations inherent to the reductionist approach, we currently identify CKD-related pseudo-syndromes and largely fail at describing the complex systemic inter-relationships set into motion by renal damage and renal dysfunction. We have just a glimpse into an exceedingly complex scenario. A mature technology for a system-analysis approach to physiology and pathophysiology now exists. System biology will allow in depth understanding of complex diseases like CKD [1] and will set the stage for predictive, preventive and personalized medicine, a long-standing dream of doctors and patients alike. 


\section{Kidney \\ Blood Pressure Research}

Kidney Blood Press Res 2014;39:134-141

\begin{tabular}{l|l}
\hline DOI: $10.1159 / 000355788$ & (c 2014 S. Karger AG, Basel \\
\hline
\end{tabular}

Published onlıne: July 29, 2014

www.karger.com/kbr

\section{Disclosure Statement}

The authors of this work declare that they do not have any conflict of interests.

\section{References}

-1 Atzler D, Schwedhelm E, Zeller T: Integrated genomics and metabolomics in nephrology. Nephrol Dial Transplant 2013, DOI 10.1093/ndt/gft492.

-2 Guyton AC: Dominant role of the kidneys and accessory role of whole-body autoregulation in the pathogenesis of hypertension. Am J Hypertens 1989;2:575-585.

-3 DiBona GF, Sawin LL: Renal nerve activity in conscious rats during volume expansion and depletion. Am J Physiol 1985;248:F15-F23.

4 Baldock PA, Lee NJ, Driessler F, Lin S, Allison S, Stehrer B, Lin EJ, Zhang L, Enriquez RF, Wong IP, McDonald MM, During M, Pierroz DD, Slack K, Shi YC, Yulyaningsih E, Aljanova A, Little DG, Ferrari SL, Sainsbury A, Eisman JA, Herzog H: Neuropeptide Y knockout mice reveal a central role of NPY in the coordination of bone mass to body weight. PLoS One 2009;4:e8415.

5 Lohmeier TE, Mizelle HL, Reinhart GA: Role of atrial natriuretic peptide in long-term volume homeostasis. Clin Exp Pharmacol Physiol 1995;22:55-61.

6 O'Connor PM, Cowley AW, Jr: Modulation of pressure-natriuresis by renal medullary reactive oxygen species and nitric oxide. Curr Hypertens Rep 2010;12:86-92.

7 Kielstein JT, Simmel S, Bode-Boger SM, Roth HJ, Schmidt-Gayk H, Haller H, Fliser D: Subpressor dose asymmetric dimethylarginine modulates renal function in humans through nitric oxide synthase inhibition. Kidney Blood Press Res 2004;27:143-147.

8 Heineke J, Kempf T, Kraft T, Hilfiker A, Morawietz H, Scheubel RJ, Caroni P, Lohmann SM, Drexler H, Wollert KC: Downregulation of cytoskeletal muscle LIM protein by nitric oxide: impact on cardiac myocyte hypertrophy. Circulation 2003;107:1424-1432.

-9 Sverdlov AL, Ngo DT, Nightingale AK, Rajendran S, Mishra K, Heresztyn T, Ritchie RH, Marwick TH, Frenneaux MP, Horowitz JD: The endogenous NOS inhibitor asymmetric dimethylarginine (ADMA) predicts LV mass independent of afterload. Nitric Oxide 2011;25:41-46.

10 Zoccali C, Mallamaci F, Maas R, Benedetto FA, Tripepi G, Malatino LS, Cataliotti A, Bellanuova I, Boger R: Left ventricular hypertrophy, cardiac remodeling and asymmetric dimethylarginine (ADMA) in hemodialysis patients. Kidney Int 2002;62:339-345.

11 Scalera F, Borlak J, Beckmann B, Martens-Lobenhoffer J, Thum T, Tager M, Bode-Boger SM: Endogenous nitric oxide synthesis inhibitor asymmetric dimethyl L-arginine accelerates endothelial cell senescence. Arterioscler Thromb Vasc Biol 2004;24:1816-1822.

12 Quarles LD: Endocrine functions of bone in mineral metabolism regulation. J Clin Invest 2008;118:38203828.

13 Quarles LD: Skeletal secretion of FGF-23 regulates phosphate and vitamin D metabolism. Nat Rev Endocrinol 2012;8:276-286.

$\checkmark 14$ Faul C, Amaral AP, Oskouei B, Hu MC, Sloan A, Isakova T, Gutierrez OM, Aguillon-Prada R, Lincoln J, Hare JM, Mundel P, Morales A, Scialla J, Fischer M, Soliman EZ, Chen J, Go AS, Rosas SE, Nessel L, Townsend RR, Feldman HI, St John SM, Ojo A, Gadegbeku C, Di Marco GS, Reuter S, Kentrup D, Tiemann K, Brand M, Hill JA, Moe OW, Kuro O, Kusek JW, Keane MG, Wolf M: FGF23 induces left ventricular hypertrophy. J Clin Invest 2011;121:4393-4408.

15 Grassi G, Quarti-Trevano F, Seravalle G, Arenare F, Volpe M, Furiani S, Dell'oro R, Mancia G: Early sympathetic activation in the initial clinical stages of chronic renal failure. Hypertension 2011;57:846-851.

16 Grassi G, Seravalle G, Ghiadoni L, Tripepi G, Bruno RM, Mancia G, Zoccali C: Sympathetic nerve traffic and asymmetric dimethylarginine in chronic kidney disease. Clin J Am Soc Nephrol 2011;6:2620-2627.

17 Converse RL, Jr., Jacobsen TN, Toto RD, Jost CM, Cosentino F, Fouad-Tarazi F, Victor RG: Sympathetic overactivity in patients with chronic renal failure. N Engl J Med 1992;327:1912-1918.

18 Ligtenberg G, Blankestijn PJ, Oey PL, Klein IH, Dijkhorst-Oei LT, Boomsma F, Wieneke GH, van Huffelen AC, Koomans HA: Reduction of sympathetic hyperactivity by enalapril in patients with chronic renal failure. $\mathrm{N}$ Engl J Med 1999;340:1321-1328. 


\section{Kidney \\ Blood Pressure Research}

Zoccali/Tripepi/Dounousi/Mallamaci: CKD and Inter-Organ Cross-Talk

19 Hering D, Mahfoud F, Walton AS, Krum H, Lambert GW, Lambert EA, Sobotka PA, Bohm M, Cremers B, Esler MD, Schlaich MP: Renal denervation in moderate to severe CKD. J Am Soc Nephrol 2012;23:1250-1257.

-20 Amann K, Hofstetter J, Campean V, Koch A, Gross ML, Veelken R, Ritz E: Nonhypotensive dose of betaadrenergic blocker ameliorates capillary deficits in the hearts of rats with moderate renal failure. Virchows Arch 2006;449:207-214.

-21 Veelken R, Vogel EM, Hilgers K, Amann K, Hartner A, Sass G, Neuhuber W, Tiegs G: Autonomic renal denervation ameliorates experimental glomerulonephritis. J Am Soc Nephrol 2008;19:1371-1378.

22 Panuccio V, Cutrupi S, Pizzini P, Mallamaci F, Tripepi G, Zoccali C: Neuropeptide Y and markers of osteoblast activity in dialysis patients: a cross-sectional study. Am J Kidney Dis 2007;50:1001-1008.

-23 Martin FL, McKie PM, Cataliotti A, Sangaralingham SJ, Korinek J, Huntley BK, Oehler EA, Harders GE, Ichiki T, Mangiafico S, Nath KA, Redfield MM, Chen HH, Burnett JC, Jr: Experimental mild renal insufficiency mediates early cardiac apoptosis, fibrosis, and diastolic dysfunction: a kidney-heart connection. Am J Physiol Regul Integr Comp Physiol 2012;302:R292-R299.

-24 Park M, Hsu CY, Li Y, Mishra RK, Keane M, Rosas SE, Dries D, Xie D, Chen J, He J, Anderson A, Go AS, Shlipak MG: Associations between kidney function and subclinical cardiac abnormalities in CKD. J Am Soc Nephrol 2012;23:1725-1734.

25 Salvetti M, Muiesan ML, Paini A, Monteduro C, Bonzi B, Galbassini G, Belotti E, Movilli E, Cancarini G, Agabiti-Rosei E: Myocardial ultrasound tissue characterization in patients with chronic renal failure. J Am Soc Nephrol 2007;18:1953-1958.

-26 Shi B, Ni Z, Zhou W, Yu Z, Gu L, Mou S, Fang W, Wang Q, Cao L, Yan Y, Qian J: Circulating levels of asymmetric dimethylarginine are an independent risk factor for left ventricular hypertrophy and predict cardiovascular events in pre-dialysis patients with chronic kidney disease. Eur J Intern Med 2010;21:444-448.

27 Mihout F, Shweke N, Bige N, Jouanneau C, Dussaule JC, Ronco P, Chatziantoniou C, Boffa JJ: Asymmetric dimethylarginine (ADMA) induces chronic kidney disease through a mechanism involving collagen and TGF-beta1 synthesis. J Pathol 2011;223:37-45.

28 Matsumoto Y, Ueda S, Yamagishi S, Matsuguma K, Shibata R, Fukami K, Matsuoka H, Imaizumi T, Okuda S: Dimethylarginine dimethylaminohydrolase prevents progression of renal dysfunction by inhibiting loss of peritubular capillaries and tubulointerstitial fibrosis in a rat model of chronic kidney disease. J Am Soc Nephrol 2007;18:1525-1533.

29 Ravani P, Tripepi G, Malberti F, Testa S, Mallamaci F, Zoccali C: Asymmetrical dimethylarginine predicts progression to dialysis and death in patients with chronic kidney disease: a competing risks modeling approach. J Am Soc Nephrol 2005;16:2449-2455.

-30 Fliser D, Kronenberg F, Kielstein JT, Morath C, Bode-Boger SM, Haller H, Ritz E: Asymmetric dimethylarginine and progression of chronic kidney disease: the mild to moderate kidney disease study. J Am Soc Nephrol 2005; 16:2456-2461.

31 Wang Z, Lambden S, Taylor V, Sujkovic E, Nandi M, Tomlinson J, Dyson A, McDonald N, Caddick S, Singer M, Leiper J: Pharmacological inhibition of DDAH1 improves survival, hemodynamics and organ function in experimental septic shock. Biochem J 2014;460:309-316.

32 Zoccali C, Leonardis D, Tripepi G, Enia G, Mallamaci F: FGF23 and Asymmetrical Dimethylarginine (ADMA) Are Interactive Factors in the High Risk for CKD Progression in Stage 2-5 CKD Patients. J Am Soc Nephrol 2012;23:175A.

-33 Saito Y, Yamagishi T, Nakamura T, Ohyama Y, Aizawa H, Suga T, Matsumura Y, Masuda H, Kurabayashi M, Kuro-o M, Nabeshima Y, Nagai R: Klotho protein protects against endothelial dysfunction. Biochem Biophys Res Commun 1998;248:324-329.

34 Nakamura T, Saito Y, Ohyama Y, Masuda H, Sumino H, Kuro-o M, Nabeshima Y, Nagai R, Kurabayashi M: Production of nitric oxide, but not prostacyclin, is reduced in klotho mice. Jpn J Pharmacol 2002;89:149156.

-35 Zoccali C, Goldsmith D, Agarwal R, Blankestijn PJ, Fliser D, Wiecek A, Suleymanlar G, Ortiz A, Massy Z, Covic A, Martinez-Castelao A, Jager KJ, Dekker FW, Lindholm B, London G: The complexity of the cardio-renal link: taxonomy, syndromes and diseases. Kidney Int Suppl 2011;1:2-5.

-36 Cozzolino M, Ureña-Torres P, Vervloet MG, Brandenburg V, Bover J, Goldsmith D, Larsson TE, Massy ZA, Mazzaferro S: Is chronic kidney disease-mineral bone disorder (CKD-MBD) really a syndrome? Nephrol Dial Transplant 2014, DOI 10.1093/ndt/gft514. 